This item was submitted to Loughborough's Research Repository by the author.

Items in Figshare are protected by copyright, with all rights reserved, unless otherwise indicated.

\title{
Importance of descending skill for performance in fell races: a statistical analysis of race results
}

PLEASE CITE THE PUBLISHED VERSION

http://dx.doi.org/10.1515/jqas-2013-0075

\section{PUBLISHER}

(C) De Gruyter

\section{VERSION}

VoR (Version of Record)

\section{PUBLISHER STATEMENT}

This work is made available according to the conditions of the Creative Commons Attribution-NonCommercialNoDerivatives 4.0 International (CC BY-NC-ND 4.0) licence. Full details of this licence are available at: https://creativecommons.org/licenses/by-nc-nd/4.0/

\section{LICENCE}

CC BY-NC-ND 4.0

\section{REPOSITORY RECORD}

Kay, Anthony. 2019. "Importance of Descending Skill for Performance in Fell Races: A Statistical Analysis of Race Results”. figshare. https://hdl.handle.net/2134/16479. 


\section{Anthony Kay* \\ Importance of descending skill for performance in fell races: a statistical analysis of race results}

\begin{abstract}
The ratio of uphill pace to downhill pace in a foot race up and down a single mountain is used as a measure of a competitor's descending skills - those qualities which are needed for fast descent but not for ascent. For the set of competitors in each of 44 races on seven courses of differing gradients and terrain roughnesses, we calculate the variance of this pace ratio and do linear regressions of pace ratio on finish time and on competitors' age. The variances tend to be greater for races on steeper and rougher terrain, indicating a greater influence of descending skills on actual descent speeds in these races. The regression analysis shows a clear negative correlation with finish time, indicating that faster finishers tend to be those with better descending skills, but there is little evidence of correlation with age. Significant differences between the sexes are only found in races on the most difficult terrain, where men display better descending skills than women.
\end{abstract}

Keywords: descending skills; hill running; linear regression.

*Corresponding author: Anthony Kay, Department of Mathematical Sciences, Loughborough University, Loughborough LE11 3TU, UK, Tel./Fax: 01509 222878, e-mail: A.Kay@lboro.ac.uk

\section{Introduction}

An analysis of record (i.e., fastest ever) times for a selection of uphill and downhill foot races has previously been used to derive functions modelling runner's pace as a function of gradient (Kay, 2012b). These pace functions may be valid for the elite runners who achieve record times; for any other runner, we might expect the pace function to be a constant multiple of that for elite runners, but only if running performance at all gradients is purely a function of metabolism. In this case, route choice decisions of the sort examined by Kay (2012a) would be identical for all runners. However, by comparing results of physiological experiments on mountain runners on an inclined treadmill with data from mountain races, Minetti et al. (2002) found that, whereas uphill running pace does appear to depend only on metabolism, downhill pace in races is considerably slower than might be expected purely on the basis of metabolism. Staab, Agnew and Siconolfi (1992) suggest that downhill pace may be limited by biomechanical rather than physiological factors, and Liefeldt, Noakes and Dennis (1992) identify the specific biomechanical factors of impaired force generation at high muscle contraction rates and limitation of stride frequency. Thus successful downhill running requires biomechanical adaptation, not only to maximise speed but also to avoid incurring muscle damage due to the increased impact and braking forces involved in downhill running (Gottschall and Kram, 2005). On steep or rough terrain there is also the risk of injury due to falling, so there is a psychological requirement for courage in addition to the biomechanical adaptations.

We shall use the term "descending skill" to refer to the combined effect of all qualities that are required for downhill but not for uphill running, whether they be biomechanical adaptations or psychological qualities. The great diversity in downhill running speeds, which is obvious to a casual observer of any of the more rugged British fell races, must be due to different levels of acquired descending skill. Davies, Sargeant and Smith (1974) have observed that even on a treadmill, downhill running requires skills which can only be attained by practice, while the experiments by Townshend, Worringham and Stewart (2010) on overground running on comparatively gentle gradients showed greater variation in running speeds downhill than uphill. The object of the present study is to quantify the influence of descending skill on performance in mountain races; determining the role of individual biomechanical or psychological factors is beyond our scope. We shall consider how the effect of descending skill varies as a function of gradient, noting that the less quantifiable variable of terrain roughness may also play an important role. We shall also consider whether any of the variation in descending skill may be related to age and sex of the runners. For these purposes we would ideally use data from a large sample of individual athletes, each running races at various uphill and downhill gradients. Such data are not available, but there are published results lists including separate ascent and descent times for several British and American mountain races on courses which 
climb and descend a single mountain. So, while we cannot trace the performance of individual athletes over a range of uphill and downhill gradients, we can calculate the downhill and uphill pace of large numbers of runners on courses at various gradients. Here, pace is defined as the reciprocal of speed (Scarf, 2007), and we shall define pace ratio, $q$, as

$$
q=\frac{\text { Uphill pace }}{\text { Downhill pace }}
$$

Thus, as faster downhill running yields a smaller numerical value of downhill pace, runners with higher values of $q$ in a race may be displaying greater descending skill. We shall seek to make inferences about descending skill from data on pace ratio for a total of over 9000 competitors in 44 races on seven courses, as detailed below. Note, however, that it is possible that some runners with high values of $q$ may have deliberately adopted a conservative uphill pace, so that pace ratio data which are supposed to represent descending skill are confounded by pacing decisions. Another related issue is the ability to quickly accommodate to the different biomechanical and physiological demands of downhill running after reaching the summit following a prolonged period of uphill running, although this would probably have a very small influence on $q$ and could in any case be regarded as an element of descending skill.

\section{Data sources}

Our requirement is for results lists showing runners' times at the summit as well as at the finish of a race which climbs and descends a single mountain. We have found five UK and two US mountain race courses that have published results lists satisfying this requirement for at least two years' running of the race (at least 5 years in all but one case). In addition, the US races publish the age in years of each participant, facilitating analysis of the dependence of performance on age; the UK race results only classify runners as Senior (typically defined as 18-39 years, but with some variations) or Veterans in 5-year or 10-year categories (Over-40, Over-50, etc.), sometimes with a Junior category as well; with these coarser age data, analysis of age dependence is less reliable. All data are in the public domain, on race organisers' websites.

The seven courses from which data are taken are listed below, in decreasing order of race steepness. For
Table 1 Data for seven mountain race courses (see text for definitions of symbols).

\begin{tabular}{lrrrrr}
\hline Course & $\begin{array}{r}\boldsymbol{L} \\
\text { metres }\end{array}$ & $\begin{array}{r}\boldsymbol{H} / \\
\text { metres }\end{array}$ & $\boldsymbol{m}$ & $\mathbf{Y}$ & $\begin{array}{r}\text { Range } \\
\text { of } \boldsymbol{N}\end{array}$ \\
\hline Mount Marathon (men) & 5000 & 911 & 0.364 & 5 & $302-329$ \\
Mount Marathon (women) & 5000 & 911 & 0.364 & 5 & $270-304$ \\
Scafell Pike & 7200 & 900 & 0.250 & 7 & $33-84$ \\
Pen y Fan (up) & 3450 & 610 & 0.177 & 7 & $45-172$ \\
Pen y Fan (down) & 2450 & 580 & 0.237 & 7 & $45-172$ \\
Slieve Donard & 8800 & 850 & 0.193 & 7 & $85-130$ \\
Ben Lomond & 12600 & 960 & 0.152 & 2 & $121-196$ \\
Snowdon & 16000 & 980 & 0.123 & 6 & $430-501$ \\
Barr Trail & 20200 & 1106 & 0.109 & 5 & $333-354$ \\
\hline
\end{tabular}

each one, we give a brief description of the course, and we tabulate the following data in Table 1: total length $L$; vertical ascent/descent $H$; mean gradient $m$; number of years' races on the course from which data have been used, $Y$; number of runners in each year, $N$, given as a range from the least to the greatest number in the dataset. In one case where the uphill and downhill routes are significantly different, lengths, ascent/descent and mean gradients are quoted separately for the uphill and downhill sections; where ascent and descent routes are identical, $m=2 H / L$. There is also one course on which men and women race separately, and so separate lines in the table are allocated.

1. Mount Marathon Race (Alaska): probably the steepest up-and-down footrace in the world; ${ }^{1}$ several hundred metres of gently inclined road at the start and finish, with the rest being mostly on very steep scree slopes; descent route differs slightly from ascent, and finish is one block away from start. Separate men's and women's races.

2. Scafell Pike race (England): straight up and down the mountain, on footpath and grassy hillside, but very rocky near summit.

3. Pen-y-Fan race (Wales): ascent and descent routes are different, with ascent visiting the subsidiary summit of Corn Du; terrain is paths and grassy hillside (see Figure 1).

4. Slieve Donard race (Northern Ireland): straight up and down the mountain, with a few hundred metres of flat road at the start and finish; a tourist path can be taken the whole way, but most runners opt for a more direct route over rough vegetation with scattered boulders (see Figure 2).

1 The author knows of several steeper uphill-only races in the Alps, and one steeper downhill-only race in Wales (Kay, 2012b) 


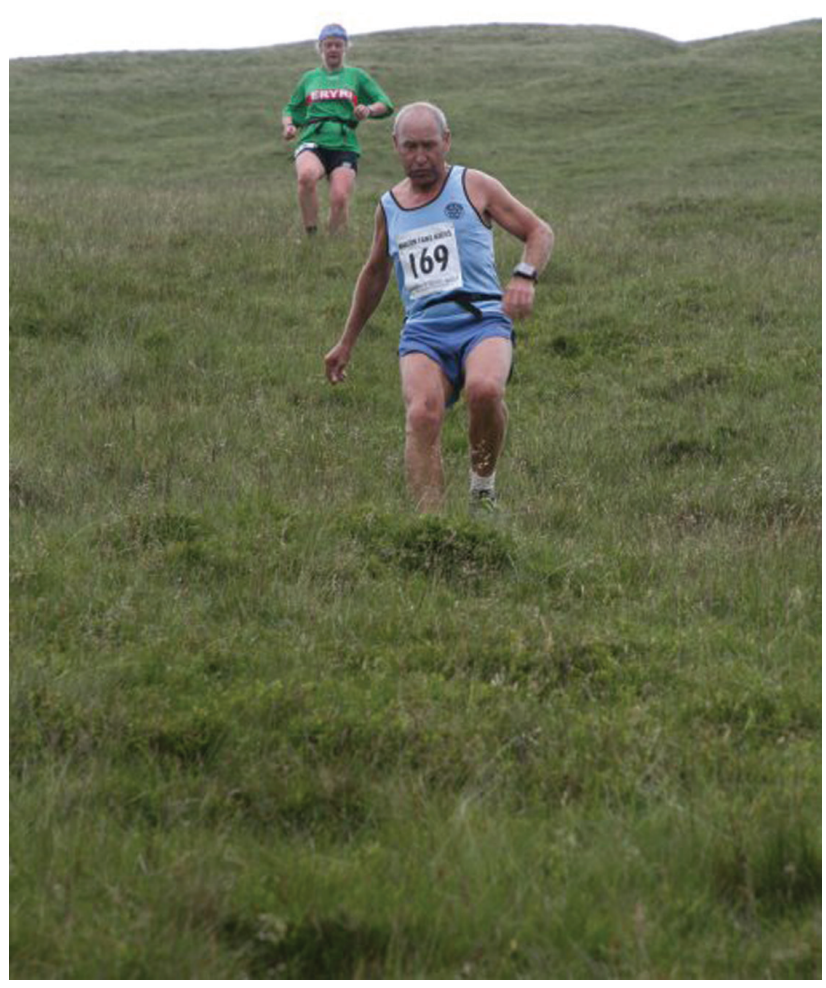

Figure 1 Runners descending the grassy slopes at the Pen y Fan race (2009). The descent is steeper overall but the terrain is easier than at Slieve Donard. Image Copyright Brecon Fans Races.

5. Ben Lomond race (Scotland): up and down a well made path with some short rocky sections; descent route differs from ascent on one short section.

6. Snowdon race (Wales): straight up and down a well made path.

7. Barr Trail Race (Colorado): straight up and down a well made path; finish location differs slightly from the start.

It appears purely coincidental that the list includes the races up and down the highest mountains in each of England, Wales and Northern Ireland, the southernmost 3000-foot mountain in Scotland, and the highest mountain in South Wales; we are not aware of any reason why the organisers of races up the most prominent peaks in the UK should be those most inclined to record summit times.

It is known that in flat road and cross-country races of similar duration to the mountain races considered here, runners do not typically run the entire race at an even pace. Studies of runners in a $10 \mathrm{~km}$ race (Lima-Silva et al. 2010) and a marathon (March et al. 2011) have shown a general slowing of the pace as the race progresses, apart from an "end spurt" when approaching the finish. A similar pacing strategy may be expected in mountain races, and it is important to separate any effect of pacing strategy on overall performance from that of descending skill. Thus we have analysed results from a control group of ten races on flat or undulating (but not mountainous) courses, for which split times at a half-way point are given in the results list: these include four $10 \mathrm{~km}$ races, three half-marathons and three full marathons. We shall henceforth refer to these as "road races", although in fact one of the ten was a multi-terrain race. Note that winning times in the Pen y Fan race are comparable with those in $10 \mathrm{~km}$ road races; winning times at Mount Marathon are between those in $10 \mathrm{~km}$ and half-marathon races; the remainder of our mountain races have winning times comparable with those in half-marathons, except for Barr Trail which has somewhat longer winning times (but shorter than in full marathons). The pace ratio $q$ for runners in the road races is simply the pace in the first half divided by the pace in the second half.

\section{Overall variation in pace ratio}

We have calculated the standard deviation $\sigma_{q}$ of the pace ratios of all competitors in each of the 44 mountain races and ten road races described above. Table 2 gives the range of $\sigma_{q}$ values found in the $Y$ races on each of the seven mountain race courses (tabulated in decreasing order of descent gradient) and each of the three classes of road race.

There is a clear trend of $\sigma_{q}$ increasing as the steepness of the race increases. The only exception to this is Slieve Donard, which has slightly higher values of $\sigma_{q}$ than Scafell Pike and Pen y Fan, but is less steep. However, the overall gradient of the Slieve Donard race is reduced by a stretch of flat road at the start and end of the course, whereas there is no road-running at Scafell Pike or Pen y Fan. Thus, on the mountain, the gradient at Slieve Donard is comparable to that of the other two races and furthermore, Figure 2 shows the terrain at Slieve Donard to be very rough (including deep heather and rocky sections) for the majority of runners who take the direct route rather the tourist path. Noting that for each of Scafell Pike, Pen y Fan and Slieve Donard there is only one instance of a race with $\sigma_{q}<0.23$, the $\sigma_{q}$ statistic appears to indicate a clear distinction between steep, rough races (the first four listed in Table 2) and easier mountain races (the remaining three in Table 2, all of which are run entirely 


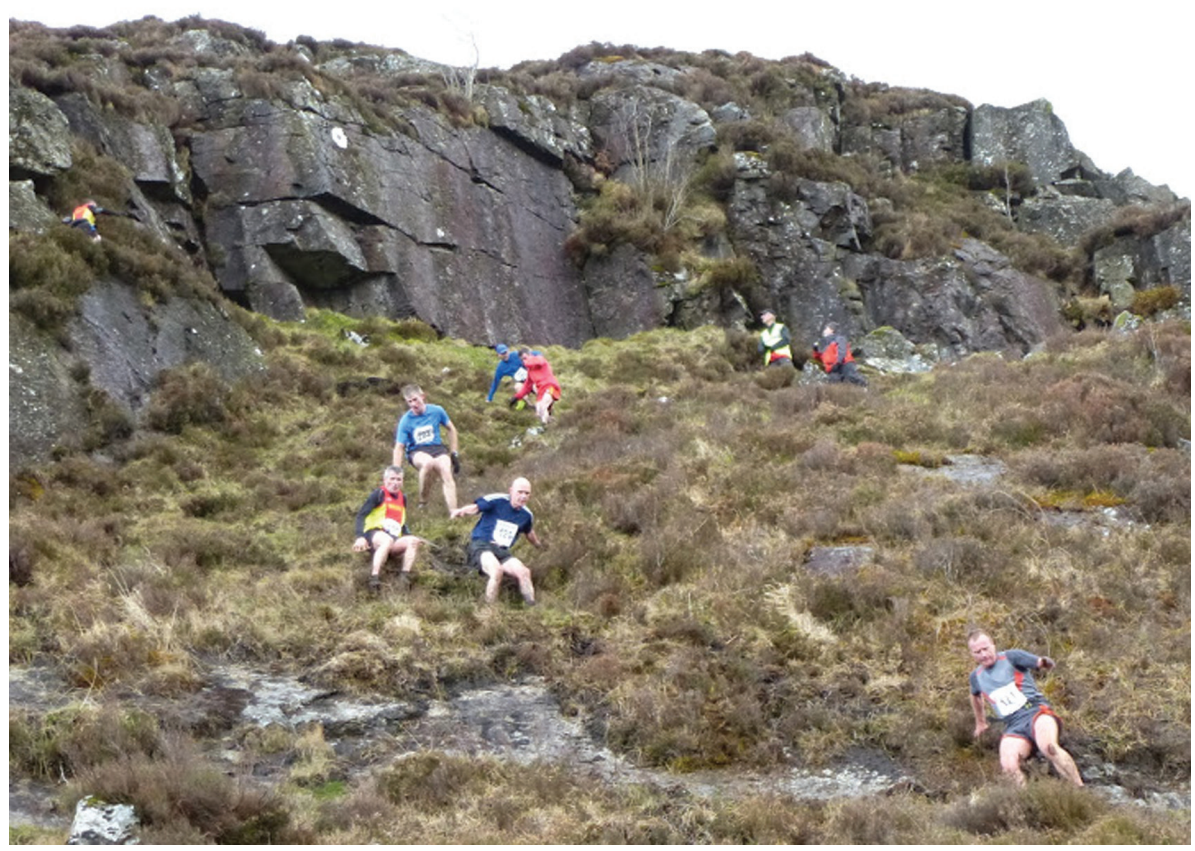

Figure 2 Runners descending the rocks and rough, boggy vegetation on the direct route at the Slieve Donard race (2013). Image Copyright Hugh Suffern.

on well-made paths). (Note that the descent route at Pen y Fan qualifies it as being within the "steep, rough" category, although the ascent is on a well-made path at a less severe gradient.) Furthermore, values of $\sigma_{q}$ are clearly greater in all the mountain races than in the road races; thus the variation in pace ratio among runners in mountain races is not simply due to varying ability to pace oneself in a race of such duration. (There is also some indication in Table 2 that $\sigma_{q}$ increases with distance in road races, i.e. that runners' pacing is more variable in longer races, but we shall not discuss this further here.)

Table 2 Range of values of $\sigma_{q}$ (standard deviation of pace ratios) found in $Y$ races on each of seven mountain race courses (listed in decreasing order of gradient) and three classes of road race.

\begin{tabular}{lrrr}
\hline Race & Gradient & $\boldsymbol{Y}$ & Range of $\boldsymbol{\sigma}_{q}$ \\
\hline Mount Marathon & 0.364 & 10 & $0.347-0.452$ \\
Scafell Pike & 0.250 & 7 & $0.173-0.362$ \\
Pen y Fan & 0.237 & 7 & $0.160-0.319$ \\
Slieve Donard & 0.193 & 7 & $0.198-0.375$ \\
Ben Lomond & 0.152 & 2 & $0.165-0.171$ \\
Snowdon & 0.123 & 6 & $0.147-0.170$ \\
Barr Trail & 0.109 & 5 & $0.133-0.151$ \\
Marathons & - & 3 & $0.071-0.095$ \\
Half-marathons & - & 3 & $0.063-0.069$ \\
10 km races & - & 4 & $0.045-0.066$ \\
\hline
\end{tabular}

It is tempting to propose a model for $\sigma_{q}$ as a function of gradient $m$; however, since the unquantifiable variable of terrain roughness acts alongside the quantifiable gradient, this has not been deemed worthwhile.

To interpret the differences in $\sigma_{q}$ between races, we need to assume that participants in all the races are sampled from the same global population of mountain runners. In this case, the much higher values of $\sigma_{q}$ in steeper, rougher races may be explained by descending skill being more important in these races (supposing always that higher $q$ values principally reflect better descending skill rather than conservative uphill pacing). The variation in descending skill is assumed to be the same in every race field, but that variation has a bigger effect on descending speed in the steeper races.

If the assumption about the sampled population were not true, that would tend to result in an inflated value of $\sigma_{q}$. The assumption probably is true for the UK races, except for the prestigious Snowdon race which does attract some road and cross-country runners who do not usually race on the mountains. Among the US races, Mount Marathon is a famous and long-established race (first run in 1915), so despite its rather extreme difficulty it does attract participants who are not habitual mountain runners, and Barr Trail does probably also attract many participants who are not specialist mountain runners. In none of these cases does the data in Table 1 suggest 
a value of $\sigma_{q}$ out of line with the general trend in $\sigma_{q}$ as a function of steepness.

\section{Correlation between pace ratio and finish time}

We have shown that descending skill influences the pace of descent more on steeper, rougher terrain, but to what extent is it correlated with overall performance? To investigate this, we have done a linear regression of pace ratio on finish time for each of the races. So that a fair comparison can be made between different races, we use as our independent variable the relative finish time $T^{\star}=T / T_{1}$, where $T$ is a runner's finish time and $T_{1}$ is that of the race winner. Since a high value of $q$ may indicate high descending skill, a significant negative correlation between $T^{\star}$ and $q$ would indicate that descending skill plays an important part in mountain running success (in races that go down as well as up), as opposed to the null hypothesis that success is determined purely by metabolic fitness. We use one-sided tests of significance for the correlation: a positive correlation would undermine our basic premise, that pace ratio measures descending skills that may contribute to (but could not detract from) success in mountain-running.

The results of every one of our 44 mountain races show a significant negative correlation between $T^{\star}$ and $q$ $(p<0.001$ in all but two cases, $p<0.02$ at one Ben Lomond race and one Barr Trail race). The slopes $\beta$ of the regression lines, $q=\alpha+\beta T^{\star}$, display a distinction between easy races and steep rough races similar to that shown by $\sigma_{q}$ : among the UK races, the 21 on steep rough courses (Scafell Pike, Pen y Fan, Slieve Donard) all have $\beta<-0.379$ (with only one having $\beta>-0.478$ ), while the eight races on easier courses all have $-0.214<\beta<-0.139$. Curiously, the US races yield smaller negative regression slopes: while the values $-0.135<\beta<-0.076$ found at Barr Trail may be attributed to the course being less steep than Snowdon or Ben Lomond, there is no obvious reason why Mount Marathon should yield $-0.594<\beta<-0.214$, with only one of its ten instances producing a value of $\beta$ as large in magnitude as the second smallest value from the 21 steep UK races. Finally, the six longer road races (marathons and half-marathons) have $\beta$ values in the range $-0.144<\beta<-0.071$, similar to those at Barr Trail, whereas the $10 \mathrm{~km}$ road races have smaller negative values, $-0.039<\beta<0$; in two of the latter, the correlation is not significant ( $p>0.1)$.

Where there is a significant negative correlation between $T^{*}$ and $q$ in a road race, our interpretation is that slower runners are less good at pacing themselves - they have a greater tendency to "fade" in the later stages of a long race; indeed, March et al. (2011) have already found that pacing is significantly more uneven for slower finishers in a marathon. For the mountain races, the greater negative values of $\beta$ (except at Barr Trail) indicate that the correlation is not simply due to the slower runners' inferior pacing, but that their descending skills are also poorer. Thus descending skill appears to contribute significantly to overall performance on all the courses except Barr Trail, and is of considerably greater importance on the steep rough courses. Possibly the reason that the latter effect is less pronounced at Mount Marathon is that the scree that dominates this mountain is easier to descend fast than the rough vegetation on Scafell Pike, Slieve Donard and Pen y Fan. However, we should note that the coefficient of determination is rather small in most cases: apart from three instances each of the Scafell Pike and Slieve Donard races, we find $R^{2}<0.5$ in all the remaining mountain races and all the road races: despite the high significance of the correlations, it would not be possible to predict descending skill from a runner's overall performance in a mountain race.

Inspection of the data from many of the races indicates that the negative correlation between $T^{\star}$ and $q$ appears stronger among the slower runners. Each results list was divided into two at the median finishing time, and a linear regression was done separately for the faster half and the slower half of the field. The negative correlation was significant at the $95 \%$ confidence level among the slower runners in all but 3 of the 44 mountain races, but was only significant among the faster runners in 16 out of 44 instances. A similar difference between faster and slower runners was also noticeable, but less pronounced, in the road races. The implication is that the participants in mountain races may be drawn from two populations: the faster finishers are experienced mountain runners, who all have broadly similar levels of descending skill (so pace ratio is independent of finishing time); the slower finishers are runners without substantial experience in the mountains, whose lack of descending skill is a significant influence on their performance. In the case of road races, the implication is that there is a population of inexperienced runners towards the back of the field who are not skilled in pacing themselves for the race distance; but the difference in regression slopes between mountain and road races suggests that pacing ability does not explain the trends in the mountain races. These ideas might be tested with a change-point regression model,

$$
q=\left\{\begin{array}{cc}
q_{0} & \left(T^{\star}<T_{c}\right) \\
q_{0}+\beta\left(T^{\star}-T_{c}\right) & \left(T^{\star}>T_{c}\right)
\end{array}\right.
$$


with $q_{0}, \beta$ and $T_{c}$ to be determined, and the demarcation between the two classes of runner at the changepoint $T_{c}$. However, given the noisiness of the data, in terms of small values of $R^{2}$ and the differences between regression results from different races on the same route, an analysis with this level of sophistication was not considered worthwhile.

Curiously, there is a positive correlation, significant at the $95 \%$ confidence level in a two-sided test, between $T^{\star}$ and $q$ in the faster half of the field in all five Barr Trail races analysed. (A significant positive correlation was also found among the faster runners in 1 year at Snowdon, and insignificant positive correlations in some other years at Snowdon and Pen y Fan.) Plotting the residuals from the linear regression of pace ratio against relative time (Figure 3) shows positive residuals tending to cluster around the median finish time, with negative residuals more dominant for $T^{\star}<1.4$ and $T^{\star}>1.8$. We conjecture that the reason for this trend may be as follows. Descending skills are of little importance for experienced runners in this race on a well-made trail of comparatively gentle gradient, but the leading runners may be habitual mountain runners with specialised strengths in uphill running, whereas those towards the middle of the field are more likely to be road or trail runners but without the mountain-running specialism. Trail-running is a well-established sport in the US, but races up and down mountains are much less common than in the UK; thus specialist mountain runners are likely to constitute only a small proportion of the field at Barr Trail, and they are likely to be mostly among the leaders. The altitude of this race, with the start at around $2000 \mathrm{~m}$ and the highest point above $3000 \mathrm{~m}$, may also favour those with experience of uphill running in the mountains.

\section{Correlation of pace ratio with age of runners}

Having established a negative correlation between pace ratio and finish time, we may ask whether this is due to both variables being a function of a third variable. Runner's age is a candidate for such a third variable: older runners might be expected to be both less agile on descents and slower overall. On the other hand, descending skills are likely to improve with experience; this effect would tend to increase pace ratio for older runners. Other personal characteristics, such as training and injury history, cannot be accounted for. Nevertheless, in spite of these difficulties and the inadequacies of the available data on age (see below), we have deemed it useful to investigate whether any correlation between pace ratio and age exists. March et al. (2011) have previously noted a significant correlation between age and pacing in a marathon race.

We have done a linear regression of pace ratio on age for each of the mountain races, except for three of the Pen y Fan races in which there were small numbers of veterans. The results lists for Mount Marathon and Barr Trail give runners' ages in years; for Scafell Pike, Slieve Donard and two years' races at Snowdon, Veterans are in 5-year categories, while in the remaining races Veterans are in

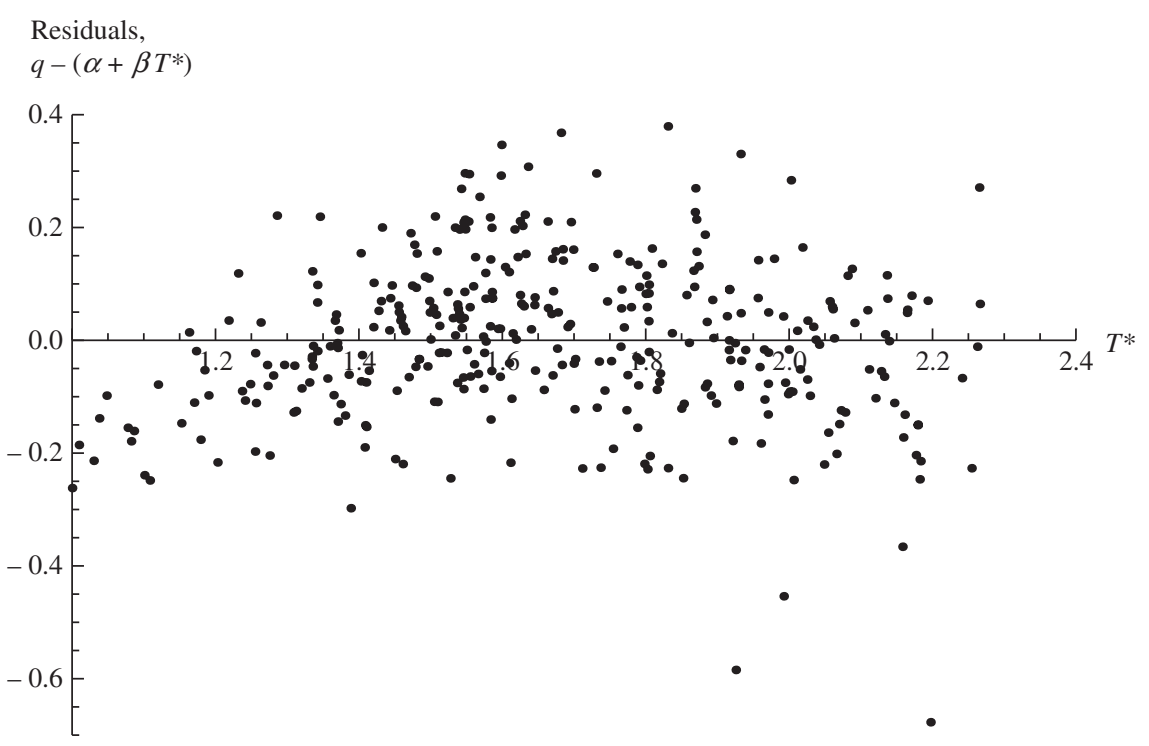

Figure 3 Residuals from the linear regression of pace ratio $q$ on relative finish time $T^{\star}$ for the 2009 Barr Trail race, plotted against $T^{\star}$. 
10-year categories. Where age is given in 5- or 10-year ranges, we have used the mid-point of the age range, e.g., 42 for a 40-44 range and 44 for a 40-49 range; similarly a mid-point age has been used for Senior and Junior categories in the UK races.

The regression analysis is somewhat inconclusive, with significant negative correlations between age and pace ratio $(p<0.05$, two-sided test to allow for descending skills to improve with experience as well as deteriorate with age) in seven out of ten Mount Marathon races but only nine out of 31 other mountain races. Among the latter, there is no clear pattern relating to the steepness of the races, and considerable variation between different years' races on the same course. The coefficient of determination $R^{2}$ for pace ratio on age is less than half that for pace ratio on relative finish time in every mountain race, and in many cases less than one-tenth.

For those races in which a significant correlation between pace ratio and age was noted, a multiple regression for pace ratio on relative finish time and runner's age was done. By examining coefficients of determination $R^{2}$ for each regression and also using a partial F-test, we determined that in general the correlation of pace ratio with age is not independent of that with finish time; however, only a small proportion of the latter can be explained as being related to age of runners. The Mount Marathon race results show a more independent age effect, but it has not been possible to determine the extent to which this is a genuine difference from the other courses or whether it is mainly due to the greater precision of the age data for this course.

\section{Differences in pace ratio between the sexes}

When considering variations between the sexes, we note first that whereas at Mount Marathon there are separate men's and women's races (with similar numbers of competitors in each), at all the other courses the men and women run together with women greatly outnumbered there are fewer than 10\% women at some of the UK races. We have not done any analysis of sex differences in races with fewer than ten women; this condition leaves only two of the Scafell Pike races, four of the Slieve Donard races and four of the Pen y Fan races in the analysis.

The simplest comparison of the sexes is by applying a two-sided Welch's t-test to the difference between their mean pace ratios. For each of the five years at Mount Marathon, we find a highly significant difference $(p<0.005)$ with men having a higher pace ratio than women. In the other steep, rough races, we find a significant difference $(p<0.05)$ favouring the men in all four Slieve Donard races, but only one Pen y Fan race and neither of the two Scafell Pike races for which the test has been applied. At the easier courses (Ben Lomond, Snowdon, Barr Trail), the women's pace ratio is higher than men's in eight out of 13 races, but the difference is insignificant ( $p>0.05)$, except in one year at Snowdon when the women had a significantly higher pace ratio. We conclude that women's descending skills are inferior to those of men on the steepest and roughest terrain, but they can cope with descents on well made paths as well as men. Alternatively, since the deficit in women's descent speed relative to men is by far the greatest in the one race where the sexes run separately, we might suppose that "women go downhill faster when they are chasing men.”

While examining the correlation between age and pace ratio, it was noticed that in each of the 5 years of the Mount Marathon Race the men had a steeper negative regression slope, with a higher degree of significance, than the women. The implication is that descending skills deteriorate more with age for men than women, so that it is the young men who cope best with Mount Marathon's notoriously steep and dangerous scree slopes. However, it was found that in only 1 of the 5 years was the difference between the regression slopes (pace ratio on age) for men and women significant ( $p<0.05$, two-sided test). Similarly, it was found that differences between regression slopes for pace ratio on relative finish time in men's and women's Mount Marathon races were only significant in one year. We have not pursued these issues for the other mountain race courses, since they have already yielded less sexdependence of pace ratio than Mount Marathon.

\section{Conclusions}

We have made a statistical analysis of the ratio of ascending pace to descending pace for each of 44 mountain races on seven different courses, with an additional sample of ten road races of three different lengths used as a control group. Our most salient results relate to the variance of pace ratio and its correlation with finish time. The variance is interpreted as quantifying the influence of runners' descending skills on their actual descending speeds in any race. This statistic shows a clear dependence on the gradient and terrain of a mountain race: among our seven courses there is a clear distinction between four steep, rough courses (high variance) and three easier 
ones (moderate variance), with the latter also being distinct from the road races (low variance), showing that descending skills are important even on easier terrain. Whereas steepness may be quantified by a single number (mean gradient), there is no simple quantitative measure of terrain roughness, but the latter quality is important. For example, the mean gradient at Slieve Donard is rather less than at Pen y Fan, but pace ratio variances tend to be higher on the former course; Slieve Donard has much rocky, heathery terrain, in contrast to the grassy terrain on Pen y Fan (see Figures 1 and 2), but the overall gradient of the Slieve Donard course is compromised by a stretch of flat ground at the foot of the mountain. A further variable that must affect mountain-running performance is weather, together with the associated variable of ground condition (wet or dry). No data on these variables have been sought, but they must be responsible for some of the year-to-year variation of statistical parameters calculated for races on each course.

The correlation between pace ratio and finish time appears at first to show a clear association between good descending skills and success in up-and-down mountain races. However, on closer examination of the data we found that the association is more between lack of descending skills and poor overall performance. The interpretation of the results is further confounded by the Barr Trail data, which indicate that some degree of "ascending skill," or at least specific training for uphill running, may be important for success on this course - whereas our interpretation of pace ratio as representing descending skill is premised on the idea that only general metabolic fitness is required for uphill running.

The evidence of women displaying inferior descending skills to men on the most difficult terrain (Mount Marathon and Slieve Donard) is confounded by the race format (single-sex vs. mixed-sex races), and there are no noticeable differences in the pace ratio data between the sexes at other races. The data relating to runners' ages are rather inconclusive; a slight decline in descending skills with age may exist and may play a minor role in the correlation between pace ratio and finish time, but significant correlations between pace ratio and age have only been found in a minority of races.

Except when examining sex differences, we have ignored what might appear to be the most fundamental statistic for pace ratio: its mean. Mean pace ratios for races may be compared with ratios calculated from the record (fastest ever) uphill and downhill paces on a course, as used by Kay (2012b); since pace ratio is negatively correlated with finish time, we would expect that the means are lower than the values for record-setters, and this is verified for 43 of the 44 races in our dataset (1 year's Scafell Pike race has an unusually high mean pace ratio, but this may be related to slight year-to-year variations in the route of the race). This has implications for the use of the functions derived by Kay (2012b) to model the variation of pace with gradient. Our assumption that pace ratio varies only due to differences in descending skill means that these pace functions are expected to be the same for all runners at all uphill gradients, apart for a constant factor which could be removed by normalising pace relative to its value at zero gradient. However, the normalised pace function for an average runner (whose pace ratio would take the mean value), or indeed any other non-elite competitor, would diverge from that in Kay (2012b) as the downhill gradient increases, since the slopes of our regression lines for pace ratio on finish time become steeper for steeper races. Our regression equations could be used to derive the expected value of pace at some given downhill gradient for a competitor with some given overall performance level relative to race winners, but this derived pace would only apply to someone with a level of descending skill typical for runners at that level of overall performance. Individuals would still need knowledge of their own descending skill in order to predict their own downhill pace; this is particularly important on steep, rough terrain, given the increased variance of pace ratio there.

Acknowledgments: This study would not have been possible without all the hard work of race organisers and their willingness to make full race results freely available. Their websites (accessed 9 July 2013) are: runpikespeak. com [Barr Trail]; www.snowdonrace.co.uk [Snowdon]; westerlandsccc.co.uk/races.php [Ben Lomond]; www.newcastleac.org/ [Slieve Donard]; www.breconfans.org.uk/peny-fan-race; [Pen y Fan] www.cfra.co.uk [Scafell Pike]; mmr. seward.com [Mount Marathon]. Several race organisers and photographers have corresponded with me and provided useful information or permission to reuse photographs: Crispin Flower, David Eiser, Hugh Suffern, John Garner, Stephen Edwards. Special thanks go to those unsung race officials who stand on mountain tops in all weathers, recording competitors' times.

\section{References}

Davies, C. T. M., A. J. Sargeant, and B. Smith. 1974. "The physiological responses to downhill running." European Journal of Applied Physiology 32: 187-194.

Gottschall, J. S. and R. Kram. 2005. "Ground reaction forces during downhill and uphill running." Journal of Biomechanics 38: 445-452. 
Kay, A. 2012a. "Route choice in hilly terrain." Geographical Analysis 44: 87-108.

Kay, A. 2012b. "Pace and critical gradient for hill runners: an analysis of race records." Journal of Quantitative Analysis in Sports 8, issue 4. DOI: 10.1515/1559-0410.1456.

Liefeldt, G., T. D. Noakes and S. C. Dennis. 1992. “Oxygen delivery does not limit peak running speed during incremental downhill running to exhaustion." European Journal of Applied Physiology 64: 493-496.

Lima-Silva, A. E., R. C. M. Bertuzzi, F. O. Pires, R. V. Barros, J. F. Gagliardi, J. Hammond, M. A. Kiss and D. J. Bishop. 2010. "Effect of performance level on pacing strategy during a 10-km running race." European Journal of Applied Physiology 108: 1045-1053.

March, D. S., P. M. Vanderburgh, P. J. Titlebaum and M. L. Hoops. 2011. "Age, sex and finish time as determinants of pacing in the marathon." Journal of Strength and Conditioning Research 25: 386-391.

Minetti, A. E., C. Moia, G. S. Roi, D. Susta and G. Ferretti. 2002. "Energy cost of walking and running at extreme uphill and downhill slopes.” Journal of Applied Physiology 93: 1039-1046.

Scarf, P. 2007. "Route choice in mountain navigation, Naismith's rule, and the equivalence of distance and climb." Journal of Sports Sciences 25: 719-726.

Staab, J. S., J. W. Agnew and S. F. Siconolfi. 1992. "Metabolic and performance responses to uphill and downhill running in distance runners." Medicine and Science in Sports and Exercise 24: 124-127.

Townshend, A. D., C. J. Worringham and I. B. Stewart. 2010. "Spontaneous pacing during overground hill running." Medicine and Science in Sports and Exercise 42: 160-169. 